See discussions, stats, and author profiles for this publication at: https://www.researchgate.net/publication/233001714

\title{
Exploring the Spiritual Needs of Adolescent Girls
}

Article in Religion and Education · May 2010

DOI: $10.1080 / 15507394.2010 .486369$

CITATIONS

13

2 authors:

6. Kaili Chen Zhang

University of Lincoln

35 PUBLICATIONS 328 CITATIONS

SEE PROFILE
READS

2,115

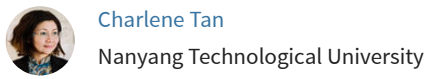

185 PUBLICATIONS 2,440 CITATIONS

SEE PROFILE 


\title{
Zhang, K.C. \& Tan, C. (2010). Exploring the spiritual needs of adolescent girls. Religion and Education, 37(2), 146-161.
}

\author{
DRAFT \\ Exploring the Spiritual Needs of Adolescent Girls
}

Kaili Chen Zhang \& Charlene Tan

\begin{abstract}
Arguing that spiritual growth is part and parcel of the personal, social and emotional development, education and care of all adolescents, this paper explores some key issues on the spiritual needs of adolescent girls within the context of holistic education. Spiritual needs refer primarily to the search for personal meaning, purpose and identity in life, as well as connectedness with others, whether divine or human. Adopting a theoretical approach based on a literature review on the development issues adolescent girls face, this paper identifies and discusses four spiritual needs of adolescent girls: body image, a sense of self, relationships, and future. This paper further suggests some practical ways for educators to foster spiritual development in the adolescent girls.
\end{abstract}

Keywords: adolescent girls; spirituality; spiritual development; spiritual needs

Adolescence is a pivotal time in all aspects of an individual's development, including physical, intellectual and emotional growth, identity formation, and interpersonal relations. One important dimension of the adolescents' development is their spirituality (a term that we shall define and discuss later). There is consistent evidence worldwide that adolescents display strong interest in spirituality and religion (e.g., Benson, Roehlkepartain, \& Rude, 2003; Dowling et al., 2004; Goldman, 1964; Warnke, 1972; Schwartz, 2001). For example, the Search Institute's survey of 218,000 6th- to 12th-grade youth during 1999-2000 in the United States reported that $69 \%$ of the youth indicated that "being religious or spiritual" is at least somewhat important, and $54 \%$ indicated it is quite or extremely important (Benson, Roehlkepartain, \& Rude, 2003). In Asia, a survey by The Straits Times on 622 Singapore residents aged 15 and above showed that $27 \%$ of believers were converted when they were below 15 years old, $19 \%$ were converted when they were aged 15-19 years (as cited in National Youth Council, 2007).

Today's public education, unfortunately, tends to place great emphasis on academic achievements and ignore the multiple dimensions of human beings; as a result it often fails to help students maximize their inner, human potentials (Miller, 2002). Although some writers have called for schools and teachers to incorporate spiritual awareness and development in the curriculum for their pupils (e.g. Tatarkowski, 1997; 
Hay, 1998; McGuire, Cooper \& Park, 2006; Author, 2009a), a review of literature shows that not much has been written on the specific spiritual needs of adolescents. This paper aims to draw the attention of researchers and educators to the issue of spirituality for adolescents, especially for adolescent girls. Arguing that spiritual growth is part and parcel of the personal, social and emotional development, education and care of all adolescents, this article identifies and explores some key issues on the spiritual needs of adolescent girls within the context of holistic education. Adopting a theoretical approach based on a literature review on the development issues adolescent girls face, the article explores how spiritual development influences the adolescent girls' self-worth and overall well-being.

This paper begins by defining the key terms used in this article, followed by identifying and discussing four main spiritual needs felt by adolescent girls: body image, a sense of self, relationships, and future. This paper concludes by suggesting some practical ways for educators working with adolescent girls to foster spiritual development in the girls. For the purpose of this paper, adolescents refer to young persons between childhood and adulthood, i.e., roughly between the age of 12-19. In this paper this term is used interchangeably with teens, young adolescents, and youths.

\section{Definitions: Spirituality, Religion, Spiritual Development and Spiritual Needs}

At the outset there is a need to explain the key terms used in this article: "spirituality", "religion", "spiritual development" and "spiritual needs." Drawing upon the distinctions made by Alexander and McLaughin (2003), spirituality can be divided into two broad categories: a religiously tethered conception of spirituality, and a religiously untethered conception of spirituality.

A religiously tethered conception of spirituality, as the name implies, is linked to or housed within the tradition of a religious faith; it "takes its shape and structure from various aspects of religion with which it is associated and that make it possible for us to identify criteria for "spiritual development" (Alexander \& McLaughlin, 2003, p. 359). We define "religion" as an organized and shared system of beliefs and practices related to a transcendent entity such as God, a higher power or ultimate truth or reality, and is closely linked to a particular faith institution (Author, forthcoming). In contrast, a religiously untethered conception of spirituality is concerned with beliefs and practices that are disconnected from religions. Not associated with any named supernatural power, institutionalized doctrines, or religious affiliations, it is about things pertaining to one's spirit or soul. It propels the search for personal meaning, purpose and identity in life, connectedness with others (whether divine or human), and a commitment to contribute to others. In terms of the search for meaning, personal cultivation, manifestations of spirituality in life, responses to aspects of the natural and human world, and the collective domain, religiously untethered spirituality tends to be unstructured, less specific, more open-ended and diffused (Alexander \& McLaughlin, 2003). While both conceptions of spirituality are relevant to adolescents, it is beyond the scope of this short paper to discuss both conceptions; we shall focus on a religiously untethered conception of spirituality and explore its relationship with the developmental needs of adolescent girls.

Spiritual development, according to Love and Talbot (1999, p. 364), is an internal process of identity development involving "a greater connectedness to self and others 
through relationships and union with community"; "deriving meaning, purpose, and direction in one's life"; and "increasing openness to exploring a relationship with an intangible and pervasive power or essence that exists beyond human existence and rational human knowing". In other words, spiritual development is essential to promote a sense of well-being with the self, others and nature, and is an alternative "to a more human, meaningful, and intellectually rigorous learning environment" (Seymour, 2004, p. 11). It involves the individual as an active agent in shaping his or her own growth as a human being (Benson, Roehlkepartain \& Rude, 2003; King \& Boyatzis, 2004). Adolescent spirituality, as noted by Dowling et al. (2004), is simply seeing life and living in new and better ways, taking something to be of great value, and defining self and relation to others in ways that move beyond the petty or material concerns to genuine concern for others.

In line with our understanding of spiritual development, "spiritual needs" refer primarily to two aspects: the search for personal meaning, purpose and identity in life; and connectedness with others, whether divine or human. We can see from our definition of spiritual needs that they are closely linked to the emotional and psychological needs of adolescents for self-awareness, understanding, love, guidance and direction. Both emotional and psychological needs, similar to spiritual needs, are about the adolescents coping with their identity crisis and emotional fluctuations, understanding themselves and others, forming self-definition and self-worth, and finding love, guidance and direction in life. We can see therefore that there are overlaps between spiritual needs on the one hand, and emotional needs and psychological needs on the other. The close relationship between these needs is not surprising as spiritual needs encompass "developmental, social-psychological phenomena, cognitive phenomena, affective and emotional phenomena, and personality" (Hill et al., 2000, as cited in Benson, Roehlkepartain \& Rude, 2003, p. 208).

However, the overlaps do not mean that spiritual needs are identical to emotional and/or psychological needs. Unlike emotional and psychological needs, spiritual needs are inherently linked to an intrinsic human capacity or what Benson, Roehlkepartain and Rude (2003) describe as the "transcendence of self toward something greater". They explain:

This impulse gives rise to such phenomena as seeking meaning and purpose, the pursuit of the sacred, and embedding one's identity within a tradition, community, or stream of thought. This propensity can be enriched or thwarted within an ecological context of family, peers, community, and, in many cases, a religious tradition and community (p. 208).

In other words, spiritual needs include but go beyond emotional and psychological concerns to broader and fundamental issues relating to one's soul and existence. For example, an adolescent girl may find her emotional and psychological needs fulfilled, at least for the time being, through attachment to a new and caring boyfriend. But her religiously-tethered spiritual needs are met only if such a relationship is aligned with her existing commitment to God, a higher power or ultimate truth or reality; her spiritual needs will not be met if, for instance, her boyfriend does not share her religion and allegiance to a religious institution which is required by her religion. For religiously- 
untethered spirituality, the adolescent's spiritual needs may be met if she is clear how her relationship with her boyfriend, who gives her emotional comfort and a blissful mental state, also positively builds up her self-identity, purpose in life and connectedness with others. These are "big questions" that can only be answered when the couple takes the time to discuss and explore a common ground in their views towards the relationship, their personal life goals and meaning of life. In short, meeting the spiritual needs contributes towards the holistic development of an individual where one's emotional and psychological needs are met and moral values are internalized. Hence educators and other professionals working with youths need to be cognizant of the spiritual needs of adolescents and introduce ways to foster their spiritual development.

\section{Adolescent Girls and their Spiritual Needs}

Before we discuss the four key spiritual needs of adolescent girls, it is instructive to have an overview of the general problems faced by adolescent girls.

\section{General Problems faced by Adolescent Girls}

There is consistent evidence that many of today's adolescent girls are susceptible to cycles of destructive behavior and crimes that lead to broken lives and incarceration (Author, 2009b). In the United States, statistics show that in recent years adolescent females represent the fastest growing segment of the juvenile justice system and that girls are being arrested for committing more violent crimes (Chesney-Lind, 2001; ChesneyLind \& Shelden, 2004; American Bar Association and National Bar Association, 2001). According to Ong (2002), the suicide rates in Japan go up every year and a large percentage of young girls are on medications for mental stress and emotional disorders. Research on female juveniles in Singapore also shows that over the last decade, an increasing number of female juveniles are involved in the justice system due to offenses such as stealing, involvement with gangs, and dealing drugs (Author, 2009b).

With more adolescent girls displaying emotional and behavioral problems, understanding girls' development is crucial. Literature indicates that factors that put adolescent girls at risk include negative attitude toward school, low self-esteem, negative body image, lack of adult supervision, physical and sexual abuse, negative peer group/involvement with gangs, substance abuse, bullying, and early sexual behaviors as well as family factors such as separation and divorce and stepfamilies (Chesney-Lind \& Shelden, 2004; Lloyd, 2005; Northwest Regional Educational Lab, 1998). Literature also shows that adolescence is a difficult passage for many girls; compared to boys, girls often experience less happiness and have lower positive self-esteem, but higher levels of anxiety and more struggles (Northwest Regional Educational Lab; Author, 2009b). Adding to the challenges faced by adolescents is that the current educational focus on testing students as part of a standardization process leaves behind a vision of the students as integral human beings, and disengages one from who the person is, from others in the world and the nature (Dantley, 2003; McNeil, 2000). 


\section{Spiritual Needs of Adolescents}

So what are the main spiritual needs of today's young adolescent girls? Following our definition of "spiritual needs", our focus is on the adolescent girls' search for personal meaning, purpose and identity in life; and connectedness with others. A review of recent literature shows that adolescent and teenage girls have their unique spiritual needs which are often reflected in their inner struggles and concerns. The following sections delineate the four key spiritual needs of adolescent girls: body image, a sense of self, relationships, and future. Although these four areas are about the adolescents' emotional and psychological needs, they are more accurately described as spiritual needs in this paper as our focus is on how these needs contribute towards the adolescents' desire to seek meaning and purpose in life within an ecological context of family, peers, community (Benson, Roehlkepartain \& Rude, 2003). In other words, the emotional and psychological needs of adolescents in their body image, a sense of self, relationships, and their future reflect an underlying personal quest to achieve a stable positive self-identity, a larger purpose in life, and a sustained connectedness with others - all the necessary conditions for one's spiritual development.

\section{Body Image}

The first two spiritual needs of adolescent girls are linked to their search for personal meaning and identity through a healthy body image and a sense of self. Studies have indicated that there are several factors that contribute to a negative body image: (a) being teased about appearance, (b) cultural tendency to judge people by their appearance, (c) peer pressure among teenage girls to be slim, and (d) the media's promotion of thinness as the ideal and advertisements of fad diets as well as weight loss programs (e.g., Body image issues for women, 2007; Brumberg, 1998). Today, cultural norms about appearance have become more rigid (Bosacki, 2001), and body image can become the major influence on the young girls' self-esteem. The self-consciousness and dissatisfaction many adolescent girls experience lead many believing that "good looks", rather than "good works", are the highest form of female perfection (Brumberg, 1998).

Societal and cultural changes have made a dramatic impact upon the lives of girls. Today, the popular cultural expectations about physical perfection have increased and the emphasis on the body as a way of defining the self is greater (Brumberg, 1998). In addition, today's societies provide less guidance and social support for young girls, despite the fact that their menstruation and sexual activity begin earlier compared to the $19^{\text {th }}$ and $20^{\text {th }}$ centuries (Brumberg, 1998). It appears that such a situation has left many girls unsupported in their development and vulnerable to the attitudes and values in movies, television, and peer pressure.

A distorted body image can lead to self-destructive behavior, such as turning to potentially dangerous weight loss methods through fasting and laxatives, and indulging in an unhealthy lifestyle. But the current self-image issue is not just an external issue resulting from a lack of societal vigilance or adult support; it is an indicator of unmet spiritual needs as an important aspect of spiritual need is the search for personal meaning and identity. According to Bosacki (1997), for example, self-image related disorders such 
as eating disorders and depression are often a result of the psychological separation of the mind and body and a lack of spiritual foundation in life.

\section{$\underline{\text { A Sense of Self }}$}

One of the critical developmental tasks of adolescence involves the establishment of a sense of self or identity. This usually entails some level of psychological separation from family, along with the embracing of new relationships beyond the sphere of family ties. Peers, heroes and heroines, other adults outside of the family, help teens feel safely connected in a web of relationships while doing the hard work of establishing their own identities. At the same time, teens develop capacities for taking a third-person perspective - seeing the self as others see them-and become acutely self-conscious (Mercer, 1993). In addition, part of the establishment of a cohesive identity during adolescence entails combining the "actual self", where the teen knows she or he is in real life, with the "ideal self" of fantasies and goals.

As adolescence is a highly peer-centered time in which self-esteem strongly relates to peer-acceptance and a sense of belonging, teens establish strong peer-group identity partly through processes of exclusion. If an adolescent is not acceptable to healthier and normal peer groups, or does not easily fit into the larger peer culture, groups such as cults and gangs may offer opportunities to be part of an intimate "in" group that fulfills many of the needs for belonging (Mercer, 1993; Warnke, 1972). Lacking the experience in decision-making, the desire for peer acceptance and a sense of belonging, and simple naiveté are causes of vulnerability for adolescents. The mixed message about the worth and role of women in today's culture also makes the establishment of a sense of identity more challenging.

Many girls are confused about how to separate from their families psychologically while at the same time embrace new relationships beyond the sphere of family ties (Bosacki, 1997; Brumberg, 1998; Author, 2008a). Some have difficulties being accepted into normal peer groups and fitting into the larger peer culture in school. They are not sure how to identify themselves with their peers while developing their own moral sense and preparing for the responsibilities and challenges of womanhood. Besides, adolescent girls who have encountered conflict, confusion, and frustration, often feel disoriented and anxious. Many youths who experience identity confusion have harmed themselves or attempted to suicide (Ong, 2002). It is the lack of a sense of belonging and identity that generates their desire to gain approval and recognition. Adolescent girls' cries of pain, help, understanding and love are often manifested in their withdrawal from the society, or demonstrated in inappropriate emotional outbursts, aggression, and rebellion, and sometimes even violence. An affiliation with gangs and cults like Satanism for troubled teens is less a religious affair than a license for a set of problematic behaviors and/or drug use (Mercer, 1993; Warnke, 1972). In its essence, these cries are indicators of spiritual needs which are grounded in personal meaning, purpose and identity in life, and connectedness with others. Just like boys, with the exposure of violence in the media, home neighborhoods and abusive relationships, adolescent girls find encouragement to defy the social and moral norms of their families and communities (e.g., Artz, 1998; Chesney-Lind \& Shelden, 2004; Lloyd, 2005). 


\section{$\underline{\text { Relationships }}$}

The third spiritual need concerns their adolescent girls' search for connectedness with others. Just like boys, girls can sit together, have fun, enjoy each other and themselves, but adolescent girls often have more complex and sometimes conflictual relationships with family members, peers, and boyfriends.

Peer-relationships. Females have the tendency to get closer to one another, and therefore are more vulnerable (Lloyd, 2005). Sharing secrets and fears create intimacy and a support system that in bad times can be turned into a weapon. Girls are bullied by their peers for a number of reasons, including: (a) appearance, such as being overweight, not dressing right, or having a different skin color, (b) resistance to the pressure to conform, (c) academic achievement, (d) sexual preferences or behavior, and (e) racial and socioeconomic backgrounds. Some girls are often worried that if they did or say anything wrong, their friends would gang up on them and decide not to be their friends (Lloyd, 2005; Northwest Regional Educational Lab, 1998). Often relationships falter not because girls care so little but because they have invested so much, and with the inability to acknowledge and manage anger, "relational bullying" becomes that way to get even (Chesney-Lind \& Shelden, 2004; Lloyd, 2005).

Family relationships. Many of today's girls are faced with a host of family related difficulties, pressures, and changes. Family breakdowns, parental conflict, hostile and rejecting relationships, as well domestic violence and abuse are some of the main reasons that explain why they are in trouble today (Chesney-Lind \& Shelden, 2004; Lloyd, 2005; Northwest Regional Educational Lab, 1998). Below are what girls often desire from their family members: (a) not to be treated as small children; (b) support and trust from parents and other members of the family to help them respond to challenges; and (c) open communication and understanding about their struggles (Author, 2008a). Indeed parents have a major influence on their children's lives, and girls are put under additional pressure when meaningful relationship with parents is lacking.

Research also shows that alienation from family relationships precedes cult membership. The strength of the parent-child relationship seems to be critical in its effects on the vulnerability of youth to cult affiliation (Schwartz, 2001). Studies also indicate that families of cult members tend to have a rigid, enmeshed structure (Robinson \& Frye, 1997). On the other hand, youths having a secure parental attachment, especially to the father, do not typically affiliate with a cult; a clash of values between parents and child often underlies cult affiliation (Sirkin, 1990)..

Sexual relationships and gender roles. Many girls faced significant challenges in sexual relationships and are confused about their gender roles (Bosacki, 2001; ChesneyLind, 2001). About $10 \%$ of them were already pregnant or have become parents when they entered the juvenile justice system (Northwest Regional Educational Lab, 1998). Although delinquency and teenage pregnancy are not equated delaying sexual activity offers girls a protective factor against trauma, unwanted pregnancy, and other risks that could lead to delinquency (Lloyd, 2005; Author, 2009b). This is consistent with Caspi, Lynam, Moffit, \& Silva's (1993) report which indicates that "puberty and boys" are two predictors of delinquency. This finding is echoed in reports from other countries. In Australia, around five per cent of children are born to teenage mothers (Body image issues for women, 2007). Reports from China claim that the abortion rates among 
teenagers have also shot up in recent years, and doctors from Youth Reproduction Health Service Centers which provide free abortion services, have to struggle to keep up with demand (e.g., Xu, 2007). As Caspi and colleagues indicate, these young mothers are more likely to be engaged in delinquent behaviors than their typical peers.

Part of the work of identity formation for teens involves establishing a sense of one's own self as sexual. During adolescence this may take the form of exaggerated gender roles, as young girls try to establish their place as feminine. What is ironic is that from early childhood, although tomboys may be tolerated and even enjoyed as children, they are often expected to naturally transform into feminine beauties at adolescence (Bosacki, 2001).

Among teens for whom negotiating the sexual issues of adolescences is especially stressful, some cults offer a resolution to the struggles by emphasizing sexual "freedom" as a primary aspect of self-gratification and encouraging people to defy conventional norms related to appropriate sexual behavior (Mercer, 1993). Instead of having to work out the tough emotional issues and the feelings that go along with adolescent sexuality, emotions become masked behind the elevation of sexual pleasure. Some cult and gang groups even subject members to sexual abuse by leaders. Mercer (1993) also points out that one of the more troublesome aspects of cults like Satanism with adolescents concerns their use of its self-gratification ethic to support the abusive treatment of others (especially young women) in the name of pleasure.

Indeed, adolescence is time of heightened awareness of sexuality. The lack of purpose and connectedness with others often results in dangerous experimentations with new behaviors, boundaries, and forms of intimacy. In fact, many young adolescent girls' search for meaning and purpose in life is often reflected in desires for excessive sexual gratification (Mercer, 1993). Adolescent girls need help and guidance in negotiating gender and family roles and in determining appropriate boundaries within relationships (Bosacki, 2001; Chesney-Lind Shelden, 2004; Northwest Regional Educational Lab, 1998).

Future

The final spiritual need of adolescent girls is their quest for personal purpose in life in terms of their future. Though the traditional progression from adolescence to adulthood has been education, employment, marriage and parenthood, life of many contemporary young girls has shifted from this traditional pattern. Many girls know that school experiences are important to career development but they could not see an authentic connection between learning and future life and work. Some were labeled as "naughty girls" since they were young, and school was just not their place so they had to figure out their "alternative" ways to success. Research shows that these girls would respond by smoking, drinking, or just sleeping (Author, 2008b). Indeed, although girls mature physically earlier, there has been no parallel acceleration in their emotional/behavioral and cognitive skills, such as the capacity to think abstractly and make wise decisions (Brumberg, 1998). Due to the lack of a sense of purpose and optimistic attitude toward life, many young girls experience isolation, marginalization and school failure. How to deal with the gnawing sense of aimlessness and emptiness that many young people hold toward life is a challenge for families and educators (Hodder, 2007). 
In the previous section, we have discussed the main spiritual needs of young girls. The following sections will discuss the implications for teachers and other professionals working with adolescent girls who face these conflicts.

\section{Suggestions for Educators Working with Adolescent Girls}

Educators and other professionals or practitioners working with adolescent girls can work towards meeting the spiritual needs of these girls through a variety of ways. A holistic perspective on education offers new opportunities to meet adolescent girls' spiritual needs by empowering them to exercise their agency to make autonomous and informed choices in life. In order that the spiritual growth of adolescent girls can be adequately addressed, we submit that the notion of curriculum and pedagogy should be carefully revisited.

First of all, the place of girls' spiritual needs, which are often reflected in personal conflicts such as body image, a sense of self, relationships, and future as discussed above, needs to be acknowledged and incorporated more widely in the school experience. As mentioned earlier, spiritual needs include but go beyond emotional and psychological concerns to broader and fundamental consideration of issues relating to one's selfidentity, purpose in life and connectedness with others. To this end, there should be opportunities for encouraging and facilitating the process of reflecting on and sharing inner emotions and life experiences between teachers/mentors and girls and among the girls themselves. To do so, practitioners should promote spiritual reflection in the adolescent girls. In its essence, spiritual reflection is about propelling adolescents to search for meaning, belonging and ultimate answers in life - an endeavor that is central to the task of identity exploration for adolescents (Benson, 1997; Hill et al., 2000; King, 2003; Author, 2009b). Given that adolescent girls are at the stage of developing and exercising their moral reasoning, reflection on spirituality provides meaningful opportunities for them to reflect on previously held beliefs (King, 2003; Loder, 1998; Markstrom, 1999), whether they are about their negative body image, lack of belonging or identity confusion.

Another role for spiritual reflection is to enable adolescent girls to develop themselves by exploring, clarifying and identifying their sense of personal calling and destiny, values and commitments for their future. As mentioned earlier, meeting the spiritual needs contributes towards the holistic development of an individual where one's emotional and psychological needs are met and moral values are internalized. Such reflection should not be imposed on adolescent girls but be offered to them as an avenue for them to freely and consciously ponder on personal issues, rights and responsibilities. Spiritual reflection should be consistent with respecting the adolescent as an active agent in shaping his or her own growth as a human being. As discussed earlier, adolescent girls often have difficulties in seeing an authentic connection between learning and future life and work. Through spiritual reflection, the adolescents' personal identities are developed by combining intellectual knowledge and abilities with personal values and convictions, leading to a lasting and holistic experience that links knowing and feeling (Dalton, 2001). Spiritual reflection can also play an instrumental role in guiding them to identify and commit to future goals. Such reflections on the greater purpose of life takes place when 
girls "ask questions about worthy commitment, moral commitment, moral responsibility, and life's inevitable transcendent claims and experiences" (Dalton, 2001, p. 24).

Spiritual reflection also provides youth with the fundamental beliefs and values for them to establish connectedness with others (Damon, 1983; Erikson, 1968; Furrow, King \& White, 2004). As pointed out earlier, adolescent girls experience complex and sometimes conflictual relationships with family members, peers, and boyfriends/relationship partners. Spiritual reflection can be a platform for adolescent girls to develop a greater self-awareness, a close affinity with others, a clearer personal destiny, and a healthy self-identity. They can acknowledge their own emotional turmoil, and ponder on their beliefs, feelings and behavior. Spiritual reflection is also needed between the adolescent girls and their parents, family members and loved ones. This will hopefully lead to honest and constructive dialogues between them that will (re)build relationships. It is important to point out that educators should guard against forcing the adolescents to examine these issues when they are not ready. Doing so may be potentially dangerous for the young people's mental health if they are already uncertain and experiencing emotional difficulties. What we are recommending is that spiritual reflection should be seen as one of the many strategies educators could use as long as they observe that the adolescent girls are ready to engage with their personal conflicts through reflection.

Apart from spiritual reflection, the second way to help the adolescent girls is for their learning and growth to include attention to a range of social and emotional skills as well as other aspects of affective and cognitive development. From a practical perspective, we need to focus on programs and activities that promote not just positive thinking, but useful ways that enhance discernment and self-acceptance as well as other aspects of spiritual development. Adolescent girls also need to learn to how to deal with the conflicts they struggle with.

Thirdly, practitioners should provide mentoring services that facilitate the girls' spiritual development. Mentoring by a caring adult is one of the most effective strategies for building character and curbing destructive behavior (Author, 2008b). Guidance provided by mentors can help girls become more reflective about their emotions and behaviors as well as spiritual well-being (Tan, 2002). A mentoring relationship can also help a girl develop coping and decision-making skills and broaden her aspirations. Further, mentors can provide individualized attention and encouragement to pursue postsecondary education or set appropriate career goals (Author, 2008b). Research also shows that when it comes to having a lasting influence on at-risk youth, there is no substitute for one-on-one mentoring. The support and encouragement adolescent girls received from mentors, especially older women, are very important to them since many of them did not have peers who share their interest and listen to their thoughts (Author, 2009). In some cases, in order to provide systematic mentoring services, the cooperation and support of religious institutions, civic organizations, and government agencies must be enlisted.

Fourthly, educators helping adolescent girls could also encourage the use of multiple intelligences, especially artistic, musical and kinesthetic intelligence. Teenagers with behavioral problems tend to be kinesthetic, visual-spatial learners, rather than linearlogical thinkers (Author, 2009a). Carr (1995) avers that the arts-literature, poetry, drama, painting and music-have a key part to play in spiritual development by 
communicating or explicating the sense of a connection between the temporal and the eternal, the finite and the infinite, the material world and the world of the soul, in human affairs" (p. 95).

One popular yet effective pedagogical approach with adolescents, based on our experience, is getting adolescents to watch films. With careful preparation and planning, good films can be used to trigger the viewers to reflect on issues of concern, ponder the meanings and implications for themselves, and finally change or modify their values, beliefs and actions (Author, 2007). Recommended films which focus on spiritual themes for youths include Mean Girls (on body image, peer pressure, identity and future); Elephant (on teenage violence and eating disorder); and High School Musical (on teenage romance, relationships and aspirations). After watching the film, journal writing can be used to promote and facilitate reflections based on the film. A journal captures the free flowing personal interpretations and expressions of a diary where the writer documents his or her learning process. Stories are spiritual in that they lift our spirits and define all aspects of humanity, including who we are and the various roles we play in life. We need to encourage girls to express themselves in journals, as the inability to tell one's own story may prevent adolescents from feeling understood. How can adolescent girls feel that adults understand them if they are unable to explain themselves? Journal writing will provide them with possible strategies to develop self-understanding and spiritual awareness.

In addition to journal writing, other reflective activities that may help to promote spiritual development include relaxation techniques, bibliotherapy, and visualization. Hue (2009)'s suggestion of using Chinese calligraphy to foster the learner's spiritual development through enhancing one's self-reflection and cultivation is also innovative and educational.

\section{Conclusion}

As suggested in this article, unmet spiritual needs are often reflected in identity crisis, loss of hope for future and purpose of life. Spiritual health not only aids students in their quest to obtain knowledge but also provides a deeper learning experience. Since an individual's personal identity is intrinsically connected with the educational processes and knowledge building, the implication is that the classroom interaction, the curriculum, programs and educational structures need to acknowledge and promote this type of connection. Hence, school experiences should consider and foster classroom pedagogies that tend to the spirit, as a spiritual foundation for schooling has the potential to ameliorate the many concerns today's young people have and to help the girls live a more balanced, positive life (Hodder, 2007).

Fortunately, in recent years, the inner world of the child has become of great interest to some professionals working with children (Bosacki, 2002). Recognizing that spirituality is an integral part of in the life, some services and programs in the West for adolescents have gradually moved toward stronger emphases on the whole child development with a focus on spiritual health (e.g., Calhoun, 2004). Supporting such an endeavor, we have highlighted in this paper the spiritual needs of adolescent girls and proposed some practical ways for practitioners to foster the girls' spiritual development in the context of holistic education. By drawing attention to and offering a preliminary study on this topic, we hope to encourage more scholars and educators to engage with, 
research and debate on this important yet under-studied dimension of adolescent development. More research, both theoretical and empirical, should be carried out to explore the spiritual needs of adolescents, taking into consideration variations such as gender, age, cultural, ethnic, and religious differences across and within countries.

\section{References}

American Bar Association and National Bar Association. (2001). Justice by gender: The lack of appropriate prevention, diversion, and treatment alternatives for girls in the justice system. Washington, DC: Author.

Artz, S. (1998). Sex, power, and the violent school girl. Toronto: Trifolium press.

Author (2007)

Author (2008a)

Author (2008b)

Author (2009a)

Author (2009b)

Benson, P. L. (1997). Spirituality and the adolescent journey. Reclaiming Children and Youth, 5, 206-209.

Benson, P. L., Roehlkepartain, E. C., \& Rude, S. P. (2003). Spiritual development in childhood and adolescence: Toward a field of inquiry. Applied Developmental Science, 7(3), 205-213.

Biological, dispositional, and contextual contributions to adolescent misbehavior. Developmental Psychology, 29(1), 19-30.

Body image issues for women. (2007). Retrieved March 27, 2007, from http://www.betterhealth.vic.gov.au/bhcv2/bhcarticles.nsf/pages/Body_image_issu es for women?OpenDocument

Bosacki, S. L. (1997). Reconnecting the mind and the body: Holistic education for preadolescents. Holistic Education Review, 10, 53-60.

Bosacki, S. L. (2001). Spirituality, gendered subjectivities, and education in adolescent girls: Canadian adolescent girls' reflections on gender-roles and their sense of self. International Journal of Children's Spirituality, 6(2), 217-221.

Bosacki, S. L. (2002). Spirituality and self in adolescent girls: Implications for a connected curriculum. International Journal of Children's Spirituality, 23(1), 55-67.

Brumberg, J. J. (1998). The Body project: An intimate history of American girls. New York: Random House.

Calhoun, J. A. (2004). The deeper principle. Reclaiming Children and Youth, 13(1), 2-4.

Carr, D. (1995). Towards a distinctive conception of spiritual education. Oxford Review of Education, 21(1), 83-98.

Caspi, A., Lynam, D., Moffitt, T. E., \& Silva, P. (1993). Unraveling girls' delinquency: Biological, dispositional, and contextual contributions to adolescent misbehavior. Developmental Psychology, 29, 19-30.

Chesney-Lind, M. (2001). What about the girls? Delinquency programming as if gender mattered. Correction Today, 63(1), 38-43.

Chesney-Lind, M., \& Shelden, R. (2004). Girls, delinquency, and juvenile justice (3 ${ }^{\text {rd }}$ ed.). Pacific Grove, CA: Brooks/Cole. 
Dalton, J. C. (2001). Career and calling: Finding a place for the spirit in work and community. In M. A. Jablonski (Ed.), The implications of student spirituality for student affairs practice (pp. 17-25). San Francisco: Jossey-Bass.

Damon, W. (1983). Social and personality development. New York: Norton.

Dantley, M. E. (2003). Purpose-driven leadership: The spiritual imperative to guiding schools beyond high-stakes testing and minimum 163 proficiency [Electronic version]. Education and Urban Society 35(3), 273 - 291.

Dowling, E. M., Gestsdottir, S., Anderson, P. M., von Eye, A., Almerigi, J., \& Lerner, R. M. (2004). Structural relations among spirituality, religiosity, and thriving in adolescence. Applied Developmental Science, 8(1), 7-16.

Erikson, E. H. (1968). Identity: Youth and crisis. New York: Norton.

Furrow, J. L., King, P. E., \& White, K. (2004). Religion and positive youth development: Identity, meaning, and prosocial concerns. Applied Developmental Science, 8(1), 17-26.

Goldman, R. (1964). Religious thinking from childhood to adolescence. London: Routledge \& Kegan Paul.

Hay, D. (1998). Why should we care about children's spirituality? Pastoral Care in Education, 16(1), 11-16.

Hill, P. C., Pargament, K. I., Hood, R. W., McCullough, M.E., Swyers, J. P., Larson, D. B., et al.? (2000). Conceptualising religion and spirituality: Points of commonality, points of departure. Journal for the Theory of Social Behavior, 30, 51-77.

Hodder, J. (2007). Young people and spirituality: The need for a spiritual foundation for Australian schooling. International Journal of Children's Spirituality, 12(2), 179190.

Hue, M-T. (2009). Promotion of spiritual development: Exploration of the self and spiritualism through the practice of Chinese calligraphy. Pastoral Care in Education, 27(1), 63-76.

King, P. E. (2003). Religion and identity: The role of ideological, social, and spiritual contexts. Applied Developmental Science, 7(3), 197-204.

Lloyd, G. (2005). Problem girls: Understanding and supporting troubled and troublesome girls and young women. London: RoutledgeFalmer.

Loder, J. E. (1998). The logic of the spirit: Human development in a theological perspective. San Francisco: Jossey-Bass.

Markstrom, C. A. (1999). Religious involvement and adolescent psychosocial development. Journal of Adolescence, 22, 205-221.

McGuire, B., Cooper, W. \& Park, M. (2006). Pastoral care, spirituality and physical education, Pastoral Care in Education, 24(4), 13-19.

McNeil, L. M. (2000). Contradictions of school reform: Educational costs of standardized testing. New York. Routledge.

Mercer, J. A. (1993). "The devil made me do it": Teens, drugs, and Satanism. Journal of Emotional and Behavioral Problems, 2(3), 11-15.

Miller, J. P. (2002). Learning from a spiritual perspective. In O'Sullivant, E. \& O'Connor, M. A. (Eds.), Expanding the boundaries of transformative learning: Essays on theory and praxis (pp. 95 - 102). New York: Palgrave.

National Youth Council. (2007). A to Z guide on youth in Singapore. Retrieved June 13, 2008, from http://www.nyc.gov.sg/research/atoz.asp\#Religion 
Northwest Regional Educational Lab. (1998). Guiding principles for promising female programming: An inventory of best practices. Portland, OR: Author.

Ong, P. (2002). Building bridges cross-culturally: A case study. In F. Tan (Ed.), Pathways: The road to mentoring. Singapore: Singapore Bible College.

Robinson, B., \& Frye, E. M. (1997). Cult affiliation and disaffiliation: Implications for counseling. Counseling \& Values, 41(2), 166-174.

Schwartz, L. L. (2001). The cult phenomenon: A turn of the century update. American Journal of Family Therapy, 29(1), 13-23.

Seymour, M. (2004). Introduction. In M. Seymour (Ed.), Educating for humanity: Rethinking the purposes of education, 1-9. Washington: The heritage institute.

Sirkin, M. (1990). Cult involvement: A systems approach to assessment and treatment. Psychotherapy, 27(1), 116-123.

Tan , F. (2002). Pathways: The road to mentoring. Singapore: Singapore Bible College.

Tatarkowski, M. (1997). Should spirituality be taught in post-compulsory education? Justifications for its inclusion in the further education curriculum. Pastoral Care in Education, 15(3), 23-29.

Warnke, M. (1972). The Satan seller. South Plainfield, NJ: Bridge.

Wright, S. A., \& Piper, E. S. (1986). Families and cults: Familial factors related to youth leaving or remaining in deviant religious groups [Electronic version]. Journal of Marriage and the Family, 48, 15-25.

Xu, X. (2007, February 16). Teen abortion rates jump in Hangzhou. China Daily, P. 4. 